\title{
Transcriptome analysis reveals rapid defence responses in wheat induced by phytotoxic aphid Schizaphis graminum feeding
}

Yong Zhang, Yu Fu, Qian Wang, Xiaobei Liu, Qian Li and Julian Chen*

\begin{abstract}
Background: Schizaphis graminum is one of the most important and devastating cereal aphids worldwide, and its feeding can cause chlorosis and necrosis in wheat. However, little information is available on the wheat defence responses triggered by S. graminum feeding at the molecular level.

Results: Here, we collected and analysed transcriptome sequencing data from leaf tissues of wheat infested with $S$. graminum at 2, 6, 12, 24 and 48 hpi (hours post infestation). A total of 44,835 genes were either up- or downregulated and differed significantly in response to aphid feeding. The expression levels of a number of genes (9761 genes) were significantly altered within $2 \mathrm{hpi}$ and continued to change during the entire $48 \mathrm{~h}$ experiment. Gene Ontology analysis showed that the downregulated DEGs were mainly enriched in photosynthesis and light harvesting, and the total chlorophyll content in wheat leaves was also significantly reduced after S. graminum infestation at 24 and $48 \mathrm{hpi}$. However, a number of related genes of the salicylic acid (SA)-mediated defence signalling pathway and MAPK-WRKY pathway were significantly upregulated at early feeding time points ( 2 and 6 hpi). In addition, the gene expression and activity of antioxidant enzymes, such as peroxidase and superoxide dismutase, were rapidly increased at 2, 6 and 12 hpi. DAB staining results showed that $\mathrm{S}$. graminum feeding induced hydrogen peroxide $\left(\mathrm{H}_{2} \mathrm{O}_{2}\right)$ accumulation at the feeding sites at $2 \mathrm{hpi}$, and increased $\mathrm{H}_{2} \mathrm{O}_{2}$ production was detected with the increases in aphid feeding time. Pretreatment with diphenylene iodonium, an NADPH oxidase inhibitor, repressed the $\mathrm{H}_{2} \mathrm{O}_{2}$ accumulation and expression levels of $\mathrm{SA}$-associated defence genes in wheat.
\end{abstract}

Conclusions: Our transcriptomic analysis revealed that defence-related pathways and oxidative stress in wheat were rapidly induced within hours after the initiation of aphid feeding. Additionally, NADPH oxidase plays an important role in aphid-induced defence responses and $\mathrm{H}_{2} \mathrm{O}_{2}$ accumulation in wheat. These results provide valuable insight into the dynamic transcriptomic responses of wheat leaves to phytotoxic aphid feeding and the molecular mechanisms of aphid-plant interactions.

Keywords: Schizaphis graminum, Transcriptomics analysis, Chlorophyll content, Defence responses, Hydrogen peroxide accumulation, NADPH oxidase

\footnotetext{
* Correspondence: chenjulian@caas.cn

State Key Laboratory for Biology of Plant Diseases and Insect Pests, Institute of Plant Protection, Chinese Academy of Agricultural Sciences, Beijing 100193, People's Republic of China
}

(c) The Author(s). 2020 Open Access This article is licensed under a Creative Commons Attribution 4.0 International License, which permits use, sharing, adaptation, distribution and reproduction in any medium or format, as long as you give appropriate credit to the original author(s) and the source, provide a link to the Creative Commons licence, and indicate if changes were made. The images or other third party material in this article are included in the article's Creative Commons licence, unless indicated otherwise in a credit line to the material. If material is not included in the article's Creative Commons licence and your intended use is not permitted by statutory regulation or exceeds the permitted use, you will need to obtain permission directly from the copyright holder. To view a copy of this licence, visit http://creativecommons.org/licenses/by/4.0/ The Creative Commons Public Domain Dedication waiver (http://creativecommons.org/publicdomain/zero/1.0/) applies to the data made available in this article, unless otherwise stated in a credit line to the data. 


\section{Background}

Plants have been interacting with herbivores for millions of years and have evolved a variety of defence mechanisms against herbivory, such as constitutive defences and inducible defences [1, 2]. Constitutive defences are physical barriers such as cell walls, waxy cuticles, and bark, protecting the plant from attacks [3-6]. Inducible defences include the rapid detection of herbivory by plants through specific recognition and signalling systems and the production of a range of products or secondary metabolites that are toxic, repellent or anti-digestive to herbivores [7-9]. Some herbivory-induced products are volatile organic compounds (VOCs) released by plants that can attract the natural enemies of herbivores, resulting in an indirect means of protection [2, 10-12].

Several phytohormones, including jasmonic acid (JA), salicylic acid (SA), ethylene (ET), abscisic acid (ABA), auxin, and cytokinins, are key mediators of plant defences [13-18]. JA and SA and their derivatives play a predominant role in modulating plant defences against pests and pathogens, respectively $[2,19]$.

The JA-dependent signalling pathway is usually activated in response to leaf-chewing herbivores, cellcontent feeders and necrotrophic pathogens [20-22]. The SA-mediated defence pathway is primarily induced by piercing-sucking herbivores and biotrophic pathogens [21]. Hemipterans have highly modified piecing-sucking mouthparts (stylets) that follow an intercellular pathway and feed on phloem sap from sieve elements (SEs) [23]. Feeding of hemipterans, like that of whiteflies and aphids, causes minimum mechanical damage in plant cells during feeding and mainly induces SA-dependent signalling defence pathway by suppressing the JA-associated defence pathway [24].

The greenbug, Schizaphis graminum, is one of the most important and devastating cereal aphids in the world, damaging plants by feeding on phloem sap and serving as a vector for transmitting viruses, such as barley yellow dwarf virus (BYDV) [25, 26]. With global warming, the potential risk of $S$. graminum infestations will increase, especially in the northern hemisphere, which could increase global food insecurity and poverty by destroying economically important crops [27]. In contrast to most other aphid species, S. graminum is a phytotoxic aphid, and its feeding can rapidly induce leaf chlorosis in susceptible plants, resulting in the deterioration of plant quality and even plant death. Previous studies have demonstrated that S. graminum feeding induced SAand JA-dependent defence pathways in sorghum (Sorghum bicolor) [28], and reactive oxygen species (ROS) levels, peroxidase (POD) and laccase activities were also increased in switchgrass (Panicum virgatum) after S. graminum feeding [29]. However, few studies have been conducted to identify the defence mechanisms in wheat in response to $S$. graminum feeding, and the mechanisms underlying the induction of damage by $S$. graminum infestation are still unclear. In the present study, we investigated the dynamic wheat responses to $S$. graminum feeding by integrating results from high-throughput RNA sequencing and cytological examination to uncover the mechanism underlying the induction of defence responses and damage symptoms by phytotoxic aphid feeding.

\section{Results}

Transcriptomic analysis of wheat leaves in response to $S$. graminum at different time points

Global transcriptomic changes in response to phytotoxic aphid feeding were examined in leaves of wheat seedlings infested with S. graminum at 2, 6, 12, 24 and 48 hpi. A total of $166.41 \mathrm{~Gb}$ of clean data were obtained from the 18 leaf samples, and each of these samples contained $\geq 7.6 \mathrm{~Gb}$ of data with Q30 quality scores $\geq 92.32 \%$ (Additional file 1). Subsequently, for each sample between 44.3 and 59.5 million reads were mapped uniquely, with roughly $5 \%$ of the total reads mapping to multiple locations (Additional file 2).

The gene expression levels were used to conduct a PCA for each of the biological replicates. Each replicate from the same group was clustered closely together, which suggested that the repeatability of each treatment was satisfactory, and the samples from different time points of $S$. graminum infestation were clustered far from each other and the control groups, which indicated that aphid feeding induced significant changes in gene expression (Fig. 1a).

The $P$ value $\leq 0.01$ (false discovery rate [FDR] adjusted) and $\log _{2}$-fold change $\left(\log _{2} \mathrm{FC}\right) \geq 1$ or $\leq-1$ were set as thresholds for DEGs in wheat leaves at different time points. Then, these identified DEGs were used for further analysis. A total of 44,835 DEGs were identified in wheat leaves at different time points $(2,6$, 12, 24 and $48 \mathrm{hpi}$ ) of aphid feeding (Additional files 3, 4, 5). Briefly, 9761 (9105 up- and 656 downregulated), 22,183 (13,935 up- and 8248 downregulated), 29,875 (16,214 up- and 13,661 downregulated), 32,741 (17, 771 up- and 14,970 downregulated) and 30,729 (17, 523 up- and 13,206 downregulated) DEGs were identified at 2, 6, 12, 24 and $48 \mathrm{hpi}$, respectively (Fig. 1b, Additional file 4). The distribution of up- and downregulated genes was calculated for each time point and are presented in a Venn diagram (Fig. 1c and d). Although a unique set of genes increased at each time point (total 74,548), the expression levels of a large 


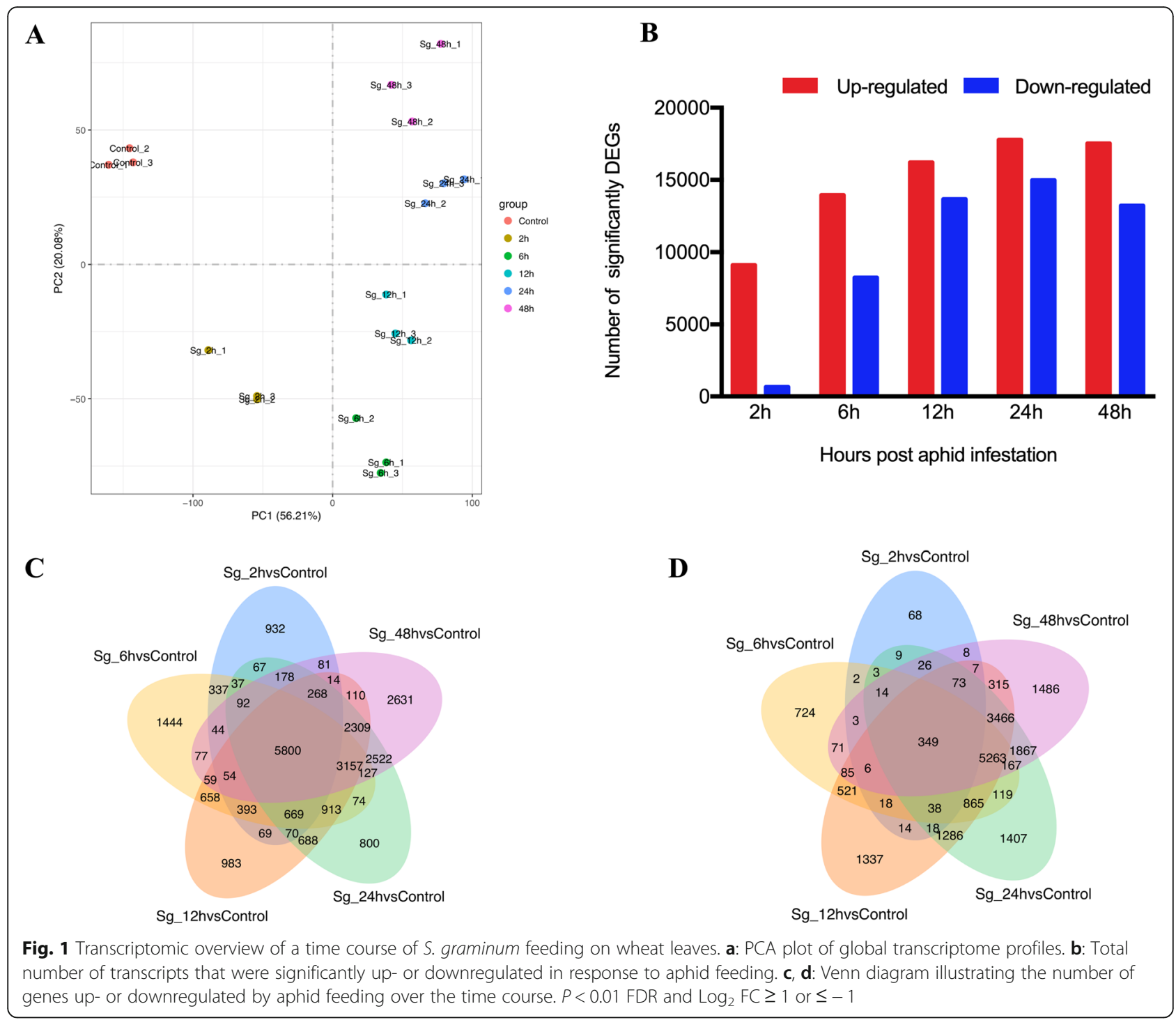

number of genes (5800) were significantly upregulated at all time points. In addition, a unique set of genes was significantly downregulated at each time point (total 50,741), and only 349 genes showed decreased expression at all five time points.

\section{Gene ontology (GO) analysis of DEGs}

GO analysis was used for the functional classification of the DEGs in wheat leaves after aphid infestation. The top 30 enriched GO terms of all DEGs are shown in Additional file 6. GO analysis of DEGs induced by $S$. graminum feeding at early time points is shown in Fig. 2. At 2 hpi (Fig. 2a, b), within the biological process category, the upregulated DEGs were mainly enriched in metabolic process, single-organism process and phosphorus metabolic process. Within the molecular function category, the largest proportion of upregulated DEGs induced by the aphid feeding was enriched in catalytic activity and transferase activity. At 6 and 12 hpi (Fig. 2c-f), the majority of the upregulated DEGs activated by the aphid feeding were enriched in metabolic processes and singleorganism processes within the biological process category, protein kinase activity and phosphotransferase activity. In the molecular function category, the upregulated DEGs were mainly enriched in catalytic activity and transferase activity.

At 6 and 12 hpi (Fig. 2c-f), within the biological process category, the downregulated DEGs were mainly enriched in photosynthesis and light reaction. In the cellular component group, greater percentages of DEGs in the cellular component category were enriched in cell and cell parts. In addition, many downregulated DEGs at 6 and $12 \mathrm{hpi}$ were also enriched in chloroplasts, further indicating the damage in wheat leaves caused by $S$. graminum feeding. 


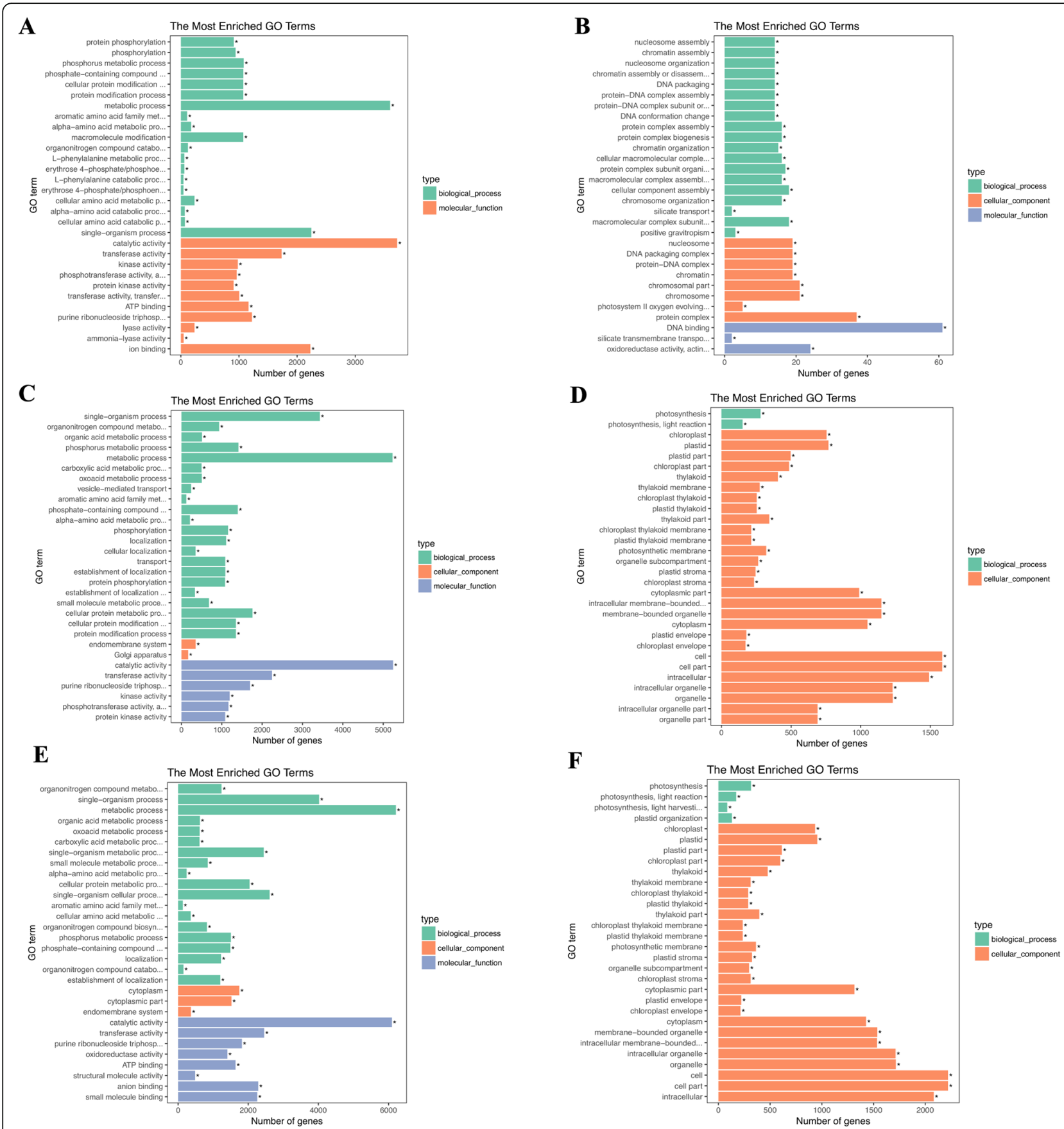

Fig. $2 \mathrm{GO}$ enrichment analysis of the differentially expressed genes (DEGs) in wheat leaves in response to S. graminum feeding at 2, 6 and $12 \mathrm{hpi}$. a: GO enrichment analysis of upregulated DEGs at 2 hpi; $\mathbf{b}$ : GO enrichment analysis of downregulated DEGs at 2 hpi; c: GO enrichment analysis of upregulated DEGs at 6 hpi; d: GO enrichment analysis of downregulated DEGs at 6 hpi; e: GO enrichment analysis of upregulated DEGs at 12 hpi; f: GO enrichment analysis of downregulated DEGs at $12 \mathrm{hpi}$

\section{Chlorophyll content in wheat leaves after S. graminum feeding}

Transcriptome analysis showed that aphid feeding negatively affected the photosynthetic processes of wheat, and the transcript levels of many light-harvesting- and photosystem-associated genes, such as ribulose-1,5- bisphosphate carboxylase, chlorophyll $a-b$ binding proteins, ferredoxin thioredoxin reductase, and PsbP family proteins, were significantly downregulated (Table 1).

The results in Fig. 3 suggested that the total chlorophyll content in wheat leaves at 2, 6 and 12 hpi was not significantly different from that of the control. However, the 
Table 1 DEGs associated with plant photosynthesis process in wheat leaves in response to S. graminum feeding

\begin{tabular}{|c|c|c|c|c|c|c|}
\hline \multirow[t]{2}{*}{ Gene Description } & \multirow[t]{2}{*}{ Gene ID } & \multicolumn{5}{|c|}{$\underline{\log _{2} \text { Fold Change }}$} \\
\hline & & $2 \mathrm{~h}$ & $6 \mathrm{~h}$ & $12 \mathrm{~h}$ & $24 \mathrm{~h}$ & $48 \mathrm{~h}$ \\
\hline \multirow[t]{8}{*}{ Ribulose-1,5-bisphosphate carboxylase } & TraesCS2B01G079100 & / & -2.49 & -3.46 & -5.92 & -5.84 \\
\hline & TraesCS2D01G065100 & / & -2.33 & -3.28 & -5.81 & -5.76 \\
\hline & TraesCS2B01G079500 & / & -2.93 & -3.71 & -6.02 & -7.35 \\
\hline & TraesCS2A01G066900 & / & -2.30 & -3.58 & -5.54 & -5.40 \\
\hline & TraesCS2B01G079400 & / & -2.21 & -2.72 & -4.28 & -3.53 \\
\hline & TraesCS2A01G067300 & / & -2.52 & -3.24 & -5.38 & -5.02 \\
\hline & TraesCS2A01G067200 & / & -2.57 & -3.66 & -5.72 & -6.11 \\
\hline & Novel03072 & / & -3.14 & -3.67 & -6.83 & -7.70 \\
\hline \multirow[t]{6}{*}{ Chlorophyll $A-B$ binding protein } & TraesCS1B01G432700 & -1.31 & -2.79 & -3.09 & -6.07 & -7.87 \\
\hline & TraesCS1A01G403300 & -1.34 & -3.05 & -3.47 & -5.46 & -6.92 \\
\hline & TraesCS2A01G204800 & / & -3.73 & -3.87 & -4.99 & -5.43 \\
\hline & TraesCS7D01G276300 & / & -3.40 & -3.10 & -6.97 & -8.54 \\
\hline & TraesCS2B01G233400 & / & -3.47 & -4.31 & -6.50 & -7.98 \\
\hline & TraesCS5D01G464800 & / & -6.20 & -5.85 & -8.98 & -11.86 \\
\hline \multirow[t]{3}{*}{ Ferredoxin thioredoxin reductase } & TraesCS6A01G234900 & / & -2.25 & -2.44 & -2.72 & -1.61 \\
\hline & TraesCS6D01G217500 & / & -2.10 & -2.35 & -3.20 & -1.76 \\
\hline & TraesCS6B01G263600 & / & -2.11 & -2.54 & -3.11 & -1.88 \\
\hline \multirow[t]{5}{*}{ PsbP domain proteins } & TraesCS2D01G255100 & / & -2.20 & -2.94 & -4.06 & -3.35 \\
\hline & TraesCS2B01G267500 & / & -2.27 & -2.81 & -3.66 & -3.04 \\
\hline & TraesCS4B01G203100 & / & -2.35 & -3.78 & -6.54 & -5.95 \\
\hline & TraesCS4D01G204000 & / & -2.21 & -3.56 & -5.61 & -4.94 \\
\hline & TraesCS4A01G101500 & / & -2.02 & -3.46 & -6.13 & -4.44 \\
\hline
\end{tabular}

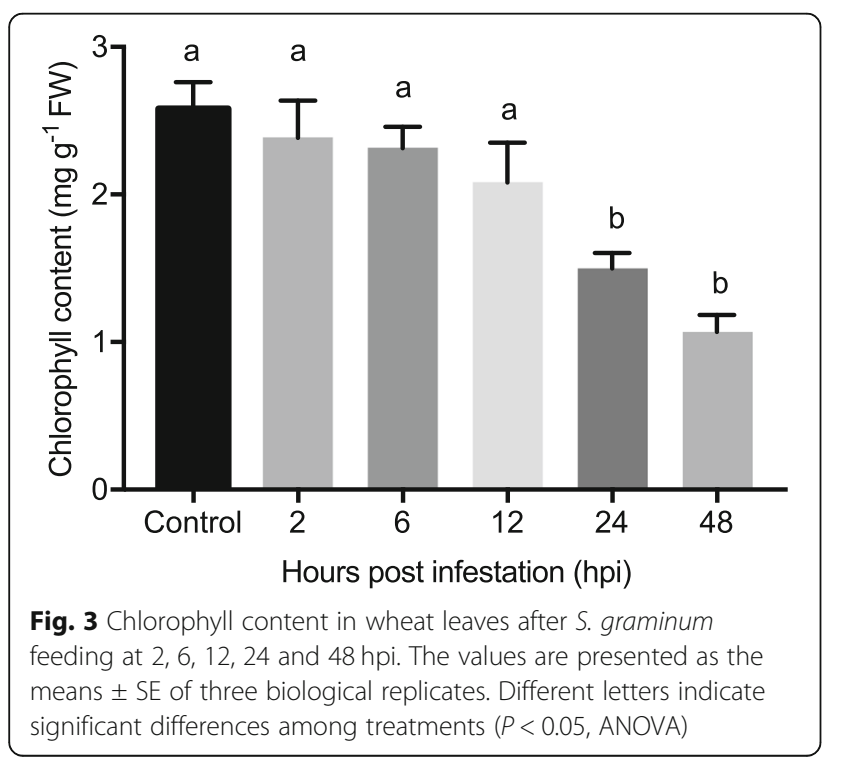

total chlorophyll content was significantly decreased to $1.49 \pm 0.10 \mathrm{mg} \mathrm{g}^{-1} \mathrm{FW}$ after $24 \mathrm{~h}$ of aphid feeding $\left(\mathrm{F}_{5,18}=\right.$ 9.447, $P=0.0001)$ and was further reduced to $1.07 \pm 0.11$ $\mathrm{mg} \mathrm{g}^{-1} \mathrm{FW}$ at $48 \mathrm{hpi}$, which was significantly lower than that of the control $\left(2.58 \pm 0.18 \mathrm{mg} \mathrm{g}^{-1} \mathrm{FW}\right)$.

Transcript levels of genes involved in SA- and JAdependent defence pathways in wheat leaves after $S$. graminum feeding

Phytohormone metabolic pathways are commonly used by plants for defence against both pests and pathogens. The transcriptome data in Table 2 showed that all six phenylalanine ammonia-lyase (PAL) genes involved in SA biosynthesis were significantly upregulated in response to $S$. graminum at different time points, and the expression levels of $P A L$ gradually decreased with increased aphid feeding time (4.96 to 16.16-fold). Furthermore, $P R$ genes that respond to SA were also significantly upregulated during all time points of aphid feeding (4.92 to 20.59-fold).

A greater effect on genes involved in JA metabolism was observed over time (Table 2). Three lipoxygenase $(L O X)$ genes were significantly upregulated by $S$. 
Table 2 DEGs involved in jasmonic acid and salicylic acid synthesis pathways in response to S. graminum feeding at different time points

\begin{tabular}{|c|c|c|c|c|c|c|c|}
\hline \multirow{2}{*}{$\begin{array}{l}\text { Plant } \\
\text { hormone }\end{array}$} & \multirow{2}{*}{$\begin{array}{l}\text { Gene } \\
\text { Description }\end{array}$} & \multirow[t]{2}{*}{ Gene ID } & \multicolumn{5}{|c|}{$\underline{\text { Log }_{2} \text { Fold Change }}$} \\
\hline & & & $2 \mathrm{~h}$ & $6 \mathrm{~h}$ & $12 \mathrm{~h}$ & $24 \mathrm{~h}$ & $48 \mathrm{~h}$ \\
\hline \multirow[t]{11}{*}{ Salicylic acid } & \multirow[t]{6}{*}{$P A L$} & TraesCS2A01G196700 & 9.89 & 9.20 & 7.91 & 6.65 & 4.95 \\
\hline & & TraesCS2B01G224300 & 11.68 & 10.40 & 8.77 & 8.26 & 7.07 \\
\hline & & TraesCS6A01G222700 & 11.71 & 11.34 & 10.28 & 8.26 & 6.65 \\
\hline & & TraesCS1B01G122800 & 11.53 & 10.96 & 9.77 & 8.82 & 7.25 \\
\hline & & TraesCS2D01G204400 & 12.13 & 11.84 & 10.52 & 10.09 & 8.95 \\
\hline & & TraesCS2B01G224000 & 16.16 & 15.31 & 14.42 & 14.10 & 12.39 \\
\hline & \multirow[t]{5}{*}{ PR Proteins } & TraesCS7D01G161200 & 12.23 & 17.10 & 19.59 & 20.59 & 19.85 \\
\hline & & TraesCS5A01G183300 & 17.13 & 12.41 & 15.17 & 15.99 & 15.03 \\
\hline & & TraesCS5B01G181500 & 6.40 & 11.09 & 14.29 & 15.29 & 14.80 \\
\hline & & Novel10567 & 4.92 & 6.09 & 6.80 & 6.59 & 6.50 \\
\hline & & TraesCS5B01G442900 & 8.34 & 10.02 & 10.96 & 11.18 & 10.23 \\
\hline \multirow[t]{13}{*}{ Jasmonic acid } & \multirow[t]{4}{*}{ LOX } & TraesCS4B01G037700 & 5.78 & 3.56 & 3.46 & 3.74 & 3.59 \\
\hline & & TraesCS7D01G244800 & 7.76 & 9.25 & 8.26 & 6.93 & 5.259 \\
\hline & & TraesCS2B01G333600 & 3.98 & 3.35 & 2.46 & 2.07 & 1.49 \\
\hline & & TraesCS7B01G145200 & 5.89 & / & / & / & / \\
\hline & \multirow[t]{5}{*}{$F A D$} & TraesCS4A01G109300 & 6.77 & 6.46 & 5.22 & 5.07 & 4.50 \\
\hline & & TraesCS2D01G279500 & 1.62 & 3.29 & 2.80 & 2.23 & 1.36 \\
\hline & & TraesCS6B01G309400 & 1.48 & 1.38 & / & / & / \\
\hline & & TraesCS6A01G280000 & 1.87 & 1.37 & / & / & -1.20 \\
\hline & & TraesCS5A01G123600 & / & / & -2.04 & -2.45 & -2.45 \\
\hline & \multirow[t]{3}{*}{$A O C$} & TraesCS6D01G314300 & 2.84 & 3.16 & 2.61 & 2.50 & 1.53 \\
\hline & & TraesCS6B01G365200 & 2.27 & 2.31 & 1.43 & 1.04 & / \\
\hline & & TraesCS6A01G334800 & 2.52 & 2.60 & 2.16 & 2.37 & 2.03 \\
\hline & $J A R 1$ & TraesCS3A01G145300 & / & -2.31 & -2.46 & -3.41 & -2.74 \\
\hline
\end{tabular}

"I" indicates no significant differences between aphid-infested and control groups

graminum feeding at different time points (1.49 to 9.25fold), and one lipoxygenase ( $L O X)$ was only upregulated at 2 hpi (5.89-fold). The expression levels of allene oxide cyclase $(A O C)$ were also significantly increased at various aphid feeding time points. In contrast, the jasmonic acid-amido synthetases (JARs) were downregulated in infested plants ( -2.31 to -3.41 -fold). There were also five fatty acid desaturase (FAD) genes that had variable expression levels, with the majority being upregulated (1.36 to 6.77-fold) during infestation. However, some were also downregulated during the three later time points ( -1.20 to -2.45 -fold), which suggests that the expression of $F A D$ genes may be fine-tuned during defence responses.

The mitogen-activated protein kinase (MAPK) cascade is a key signalling pathway of plant defence, and WRKY transcription factors (TFs) appear to be regulated by MAPKs and involved in the regulation of plant defence. The transcript levels of several MAPKs were significantly upregulated (1.01- to 3.48 -fold) in response to $S$. graminum feeding at 12, 24 and 48 hpi. Additionally, several WRKY TFs in wheat leaves were significantly induced (1.59 to 11.14-fold) in response to aphid feeding at different time points (Table 3 ).

\section{Effects of S. graminum feeding on hydrogen peroxide $\left(\mathrm{H}_{2} \mathrm{O}_{2}\right)$ accumulation and the activity of antioxidant enzymes in wheat leaves}

As shown in Table 4, S. graminum feeding upregulated various ROS-scavenging genes, such as $P O D$ and $S O D$ (superoxide dismutase), at $2 \mathrm{hpi}$. The expression levels of these two genes were increased at 6,12 and $24 \mathrm{hpi}$ and then gradually decreased at $48 \mathrm{hpi}$, but the transcript levels were still significantly increased compared with the control levels. The expression levels of catalase (CAT) genes showed no significant differences at $2 \mathrm{hpi}$ compared to the control levels. Among them, two genes were significantly downregulated at $6,12,24$ and $48 \mathrm{hpi}$, and the other two genes were significantly upregulated. 
Table 3 DEGs involved in MAPK-WRKY pathways in response to S. graminum feeding at different time points

\begin{tabular}{|c|c|c|c|c|c|c|}
\hline \multirow{2}{*}{$\begin{array}{l}\text { Gene } \\
\text { Description }\end{array}$} & \multirow[t]{2}{*}{ Gene ID } & \multicolumn{5}{|c|}{$\log _{2}$ Fold Change } \\
\hline & & $2 \mathrm{~h}$ & $6 \mathrm{~h}$ & $12 \mathrm{~h}$ & $24 \mathrm{~h}$ & $48 \mathrm{~h}$ \\
\hline \multirow[t]{8}{*}{ MAPKs } & Novel1 1623 & 1.24 & 1.44 & / & 1.32 & 1.29 \\
\hline & TraesCS4D01G198600 & / & / & 3.48 & 3.39 & 3.20 \\
\hline & TraesCS3D01G225600 & / & / & 2.30 & 2.26 & 1.25 \\
\hline & TraesCS4B01G197800 & / & / & 2.53 & 2.66 & 2.67 \\
\hline & TraesCS7B01G322900 & / & / & 2.58 & 2.64 & 2.48 \\
\hline & TraesCS4A01G106400 & / & / & 2.35 & 2.74 & 2.8 \\
\hline & TraesCS7B01G309900 & / & / & 1.64 & 1.64 & 1.52 \\
\hline & TraesCS7A01G422500 & / & / & 1.57 & 1.18 & 1.01 \\
\hline \multirow[t]{5}{*}{ WRKY } & Novel00700 & 4.12 & 5.28 & 5.36 & 7.17 & 6.40 \\
\hline & Novel01914 & 3.56 & 4.82 & 6.04 & 7.42 & 6.56 \\
\hline & Novel05138 & 6.51 & 8.40 & 9.81 & 11.06 & 11.14 \\
\hline & Novel01125 & / & 4.86 & 5.24 & 6.50 & 5.74 \\
\hline & Novel08030 & / & 2.66 & 2.30 & 2.29 & 1.59 \\
\hline
\end{tabular}

"/" indicates no significant differences between aphid-infested and control groups

The activities of three antioxidant enzymes, POD, SOD and CAT, were also examined in wheat leaves infested with aphids (Fig. 4). Compared with the control, the activity of POD was significantly increased after $6 \mathrm{~h}(19.01 \pm$ $3.94 \mathrm{U} \mathrm{mg}^{-1}$ protein) of $S$. graminum feeding and reached a peak at $48 \mathrm{hpi}\left(44.44 \pm 3.37 \mathrm{U} \mathrm{mg}^{-1}\right.$ protein; $\mathrm{F}_{5,12}=$ 10.17, $P=0.001$ ). Furthermore, the activities of SOD $\left(55.10 \pm 7.55 \mathrm{U} \mathrm{mg}^{-1}\right.$ protein; $\left.\mathrm{F}_{5,12}=5.15, P=0.009\right)$ and CAT $\left(0.20 \pm 0.038 \mathrm{U} \mathrm{mg}^{-1}\right.$ protein; $\mathrm{F}_{5,12}=7.27, P=0.002$; $)$ were significantly upregulated after $12 \mathrm{~h}$ of $S$. graminum feeding. The increased activity of ROS scavengers induced by aphid feeding suggested that S. graminum feeding induces oxidative stress in wheat leaves.
To further examine the effects of aphid feeding on oxidative stress in wheat, S. graminum-infested leaves were examined after cytological staining with 3,3'-diaminobenzidine $(\mathrm{DAB})$, which was used to detect the production of $\mathrm{H}_{2} \mathrm{O}_{2}$. As shown in Fig. 5, small and obvious brown spots were detected at $2 \mathrm{hpi}$, indicating $\mathrm{H}_{2} \mathrm{O}_{2}$ accumulation at the aphid feeding site. The number and size of the spots increased with increasing time aphid feeding time.

\section{Effects of inhibition of NADPH oxidases on $\mathrm{H}_{2} \mathrm{O}_{2}$ accumulation and defence responses in wheat leaves}

To detect the roles of plasma membrane NADPH oxidases in $\mathrm{H}_{2} \mathrm{O}_{2}$ accumulation induced by $\mathrm{S}$. graminum feeding, wheat leaves were treated with the $\mathrm{NADPH}$ oxidase inhibitor diphenylene iodonium (DPI). The DAB staining results, shown in Fig. 6a, indicate that many obvious brown spots were detected at the aphid feeding sites of infested leaves, but fewer brown spots were observed after $10 \mu \mathrm{M}$ and $25 \mu \mathrm{M}$ DPI treatments, indicating that the $\mathrm{H}_{2} \mathrm{O}_{2}$ production induced by aphid feeding was inhibited by DPI. Additionally, the $\mathrm{H}_{2} \mathrm{O}_{2}$ contents were significantly decreased to $50.60 \pm 9.51 \mu \mathrm{molg}^{-1} \mathrm{FW}$ and $33.93 \pm 3.00 \mu \mathrm{mol} \mathrm{g}^{-1} \mathrm{FW}$ in wheat leaves treated with $10 \mu \mathrm{M}$ and $25 \mu \mathrm{M}$ DPI, respectively $\left(\mathrm{F}_{2,6}=6.44\right.$, $P=0.032$ ) (Fig. 6b).

As shown in Fig. 7a and b, DPI treatment had significant effects on the expression levels of defence response genes in wheat leaves. The expression levels of the salicylic acid-related genes $P A L$ and $P R 1$ were significantly reduced in DPI-treated wheat leaves compared to the control (wheat leaves infested with aphids for $24 \mathrm{~h}$ ) $\left(\mathrm{F}_{2,6}=10.96, P=0.01 ; \mathrm{F}_{2,6}=65.53, P<0.001\right)$.

Table 4 DEGs associated with ROS scavenging in wheat leaves in response to S. graminum feeding at different time points

\begin{tabular}{|c|c|c|c|c|c|c|}
\hline \multirow[t]{2}{*}{ Gene Description } & \multirow[t]{2}{*}{ Gene ID } & \multicolumn{5}{|c|}{$\log _{2}$ Fold Change } \\
\hline & & $2 \mathrm{~h}$ & $6 \mathrm{~h}$ & $12 \mathrm{~h}$ & $24 \mathrm{~h}$ & $48 \mathrm{~h}$ \\
\hline \multirow[t]{5}{*}{ Plant peroxidase } & TraesCS2B01G125200 & 12.80 & 15.52 & 15.72 & 14.65 & 12.48 \\
\hline & TraesCS2A01G107500 & 13.98 & 16.53 & 16.85 & 15.85 & 13.60 \\
\hline & TraesCS2A01G107700 & 14.56 & 15.56 & 15.14 & 13.36 & 11.37 \\
\hline & TraesCS2B01G124800 & 12.93 & 16.87 & 17.34 & 16.67 & 14.75 \\
\hline & TraesCS2D01G107800 & 12.95 & 15.37 & 15.70 & 14.63 & 12.43 \\
\hline \multirow[t]{3}{*}{ Superoxide dismutase } & TraesCS2D01G123300 & 2.07 & 3.81 & 3.55 & 2.83 & 2.72 \\
\hline & TraesCS2A01G121200 & 1.96 & 3.85 & 3.24 & 2.53 & 2.70 \\
\hline & Novel03118 & 1.56 & 3.02 & 2.65 & 2.09 & 2.35 \\
\hline \multirow[t]{4}{*}{ Catalase } & TraesCS5A01G498000 & / & -1.52 & -1.97 & -2.57 & -1.77 \\
\hline & TraesCS6B01G330700 & / & -1.80 & -1.53 & -2.19 & -1.86 \\
\hline & TraesCS6A01G041700 & / & 3.38 & 5.90 & 4.63 & 4.65 \\
\hline & TraesCS6D01G048300 & / & 1.64 & 3.83 & 3.37 & 3.39 \\
\hline
\end{tabular}

"I" indicates no significant differences between aphid-infested and control groups 
POD

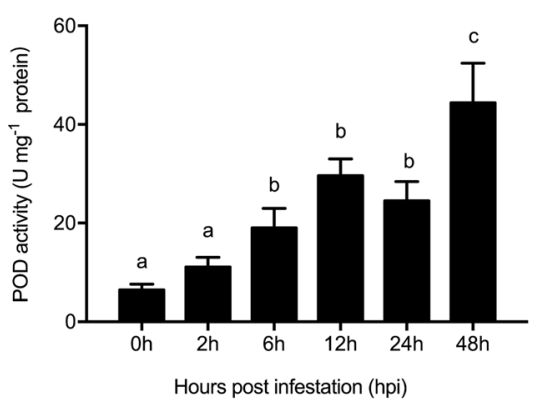

CAT

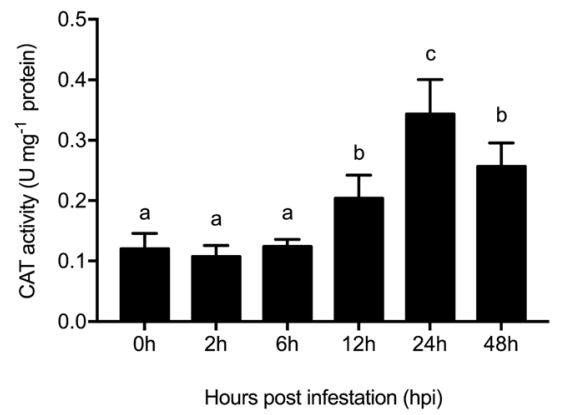

SOD

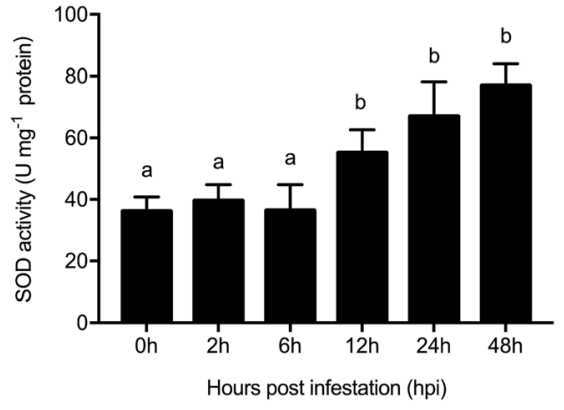

Fig. 4 Activity of the antioxidant enzymes POD, SOD and CAT in wheat leaves in response to S. graminum feeding. The values are presented as the means \pm SE of three biological replicates. Different letters indicate significant differences among treatments $(P<0.05$, ANOVA)

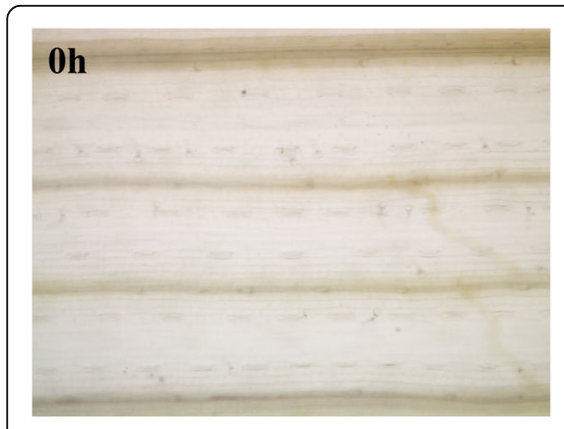

\section{$2 \mathbf{h}$}

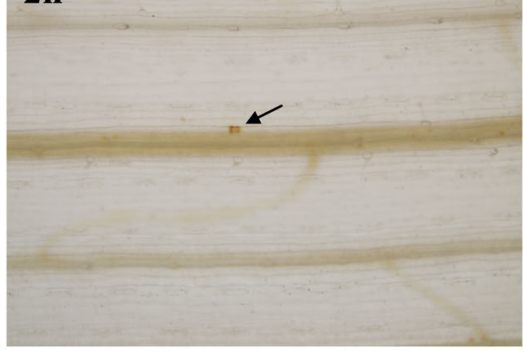

\section{$12 \mathrm{~h}$}
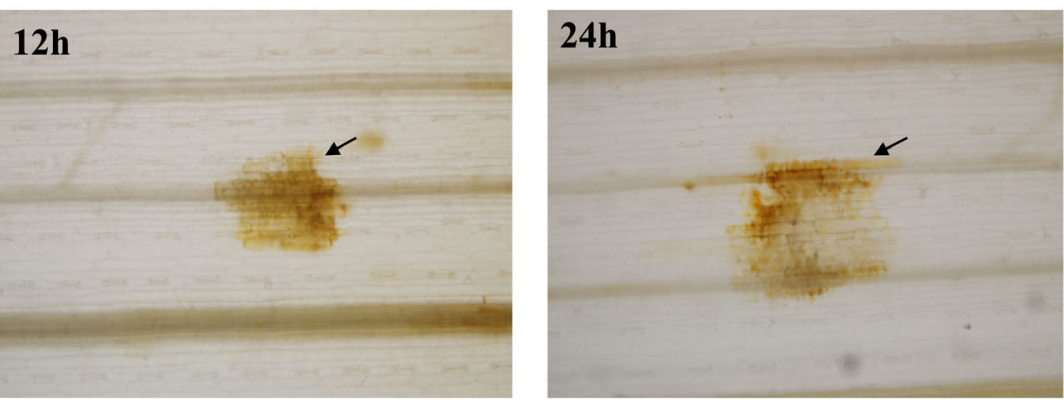

Fig. 5 Detection of $\mathrm{H}_{2} \mathrm{O}_{2}$ accumulation in wheat leaves in response to S. graminum feeding at different time points using DAB staining. Images are representative of three biological replicates
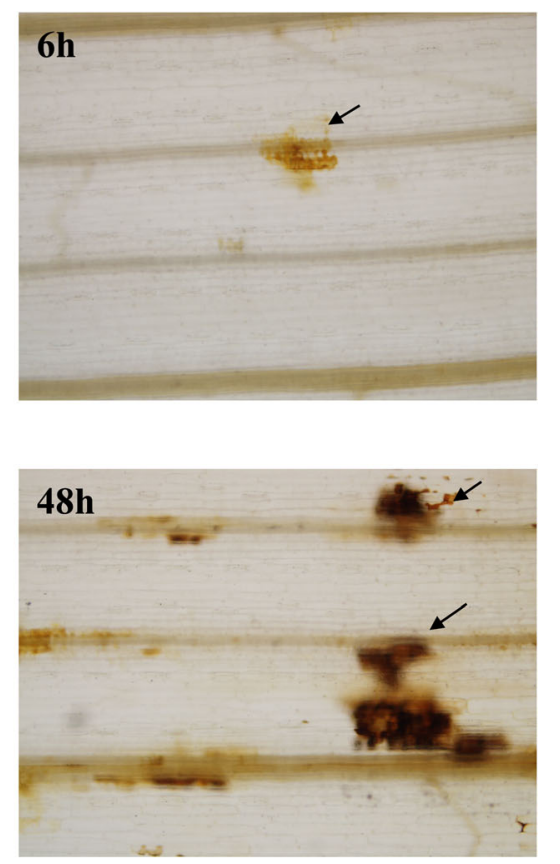


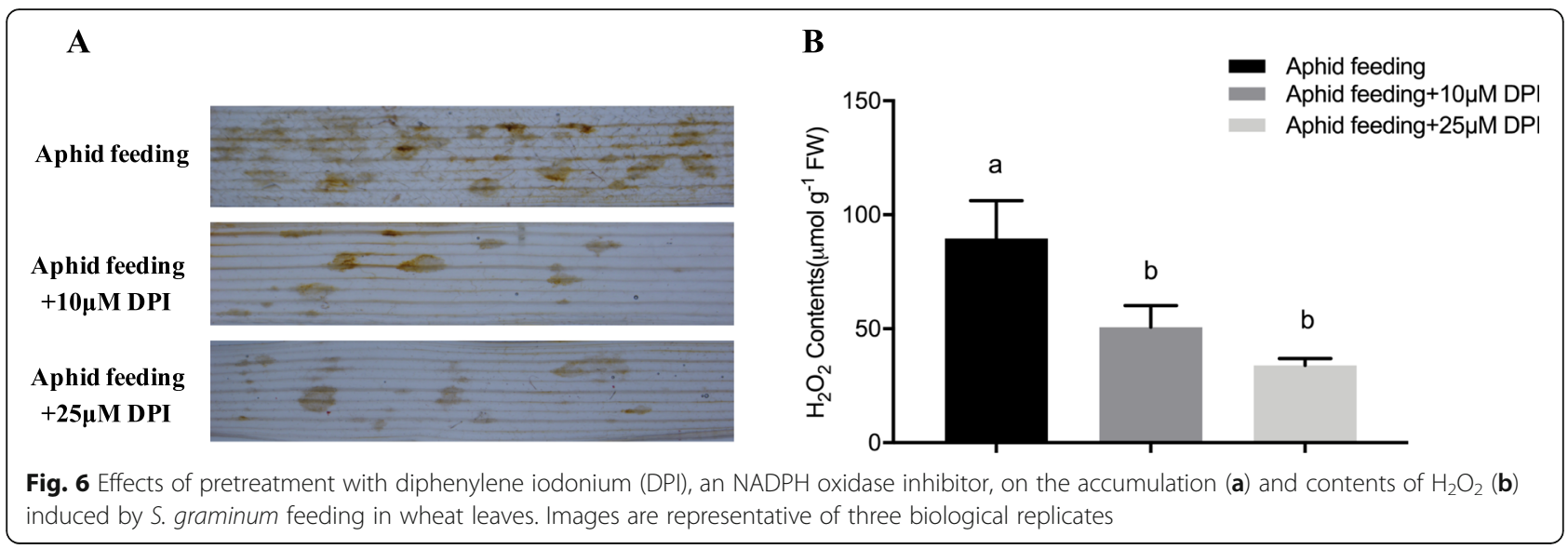

\section{Discussion}

Wheat transcriptomes are rapidly and significantly regulated in response to $S$. graminum feeding

Plants usually activate rapid responses to biotic and abiotic stress. For example, in Arabidopsis, rapid and highly localized increases in calcium was detected around the feeding sites of $M$. persicae after just a few minutes of feeding [30]. More than 500 genes associated with the primary metabolism and defence responses were significantly upregulated in peach leaves after $3 \mathrm{~h}$ of infestation by M. persicae [31]. Almost 800 genes were upregulated after $3 \mathrm{~h}$ of aphid feeding in maize [32]. Similarly, rapid and strong physiological responses were activated in

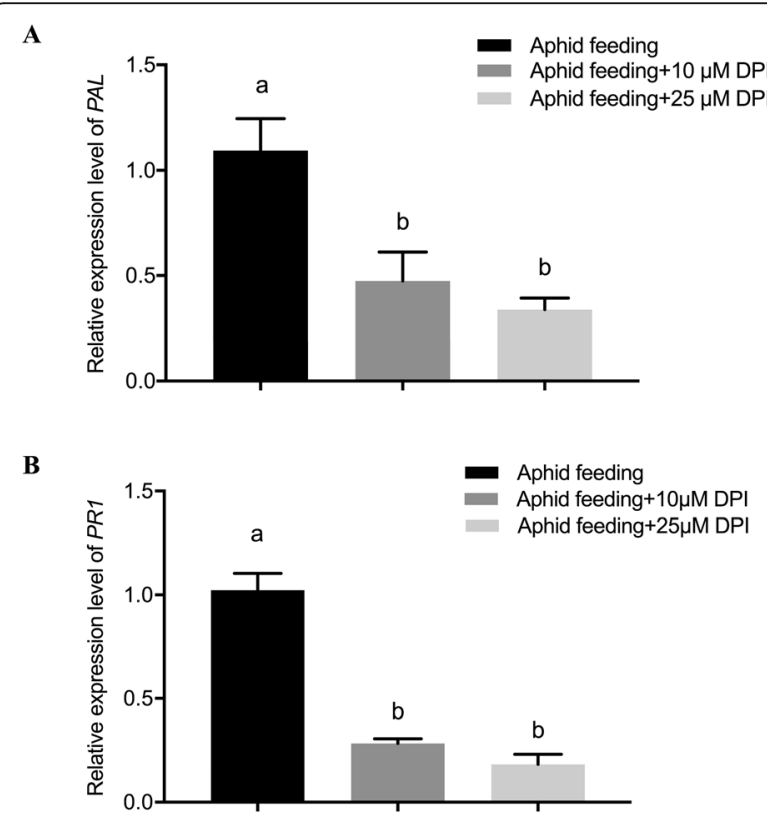

Fig. 7 Effects of pretreatment with DPI on the expression levels of the SA-associated defence genes PAL (a) and PRI (b) induced by S. graminum feeding in wheat leaves. The values are presented as the means \pm SE of three biological replicates. Different letters indicate significant differences among treatments $(P<0.05$, ANOVA) wheat by $S$. graminum feeding in our study. The transcript levels of more than 9000 genes involved in various physiological processes were significantly up- or downregulated after just $2 \mathrm{~h}$ of aphid feeding. A previous study demonstrated that severe degenerative changes were detected in vascular cells adjacent to the stylet path of susceptible wheat plants as early as $1 \mathrm{~h}$ after $S$. graminum infestation using transmission electron microscopy [33]. Cellular damage caused by aphid feeding may be responsible for the rapid and strong physiological changes in wheat leaves.

\section{S. graminum feeding results in damage to chlorophyll and} suppression of photosynthesis

As a typical phytotoxic aphid, S. graminum feeding induced obvious chlorosis in the aphid-susceptible wheat variety [34]. Consistent with previous studies [35], the total contents of chlorophyll were significantly reduced in wheat leaves after aphid infestation. Additionally, transcriptomic analysis showed that many genes involved in photosynthesis, such as ribulose-1,5-bisphosphate carboxylase and chlorophyll A-B binding protein, were significantly downregulated after $S$. graminum feeding, and downregulated DEGs at early time points of aphid feeding (after $6 \mathrm{~h}$ ) were enriched in photosynthesis and light harvesting pathways, indicating that S. graminum feeding imposed rapid damage to chlorophyll and then led to a reduction in the photosynthetic activity of the plants.

\section{Defence signalling pathway induced in wheat following challenge with $S$. graminum}

Piercing-sucking hemipteran insects, such as aphids and whiteflies, mainly induce SA-mediated defence signal pathways [36]. However, some studies have also demonstrated that genes involved in both the JA and SA defence response pathways, such as $L O X, P I s, P A L$, and $P R 1$, are significantly upregulated by aphid feeding [37-40]. Similarly, we found that $S$. graminum feeding significantly 
increased the expression levels of several genes related to the SA and JA signalling pathways. The fold changes in the expression levels of $P A L$ and $P R 1$ were very high at various aphid feeding times, suggesting that a strong $S A$ defence pathway was activated by $S$. graminum feeding, which might be responsible for the induction of chlorosis in wheat. However, the genes involved in the JA signalling pathway had variable expression levels, with the majority being upregulated during infestation but some also being downregulated during the later time points, which suggests that the expression of $F A D$ genes may be fine-tuned during defence responses. Several JAR1 (jasmonic acid resistant 1) genes were also significantly downregulated by S. graminum. JAR1 is a JA-aminosynthetase that is required to activate JA in Arabidopsis [41]. These results suggested that although JA-responsive genes were upregulated, increased JA levels or the JA defence pathway may not be activated by $S$. graminum feeding. Zhang et al. demonstrated that the SA contents in wheat leaves after $S$. graminum feeding were significantly greater than those found in wheat leaves without aphid infestation, but no significant changes were detected for the JA contents in aphid-infested wheat leaves [35].

\section{Protein phosphatases and MAPK-WRKY pathways are activated in response to $S$. graminum feeding}

At different time points of aphid feeding, many upregulated genes were enriched in protein phosphorylation. Protein phosphatases are one of the most predominant post-translational modifications (PTMs) and play a central role in signal transduction through the phosphorylation and de-phosphorylation of proteins in eukaryotes [42]. A large body of evidence demonstrates that phosphorylation is essential for immune responses in plants [43]. For example, in Arabidopsis, more than 1170 phosphopeptides from 472 phosphoproteins were identified after treatments with flg22 or xylanase, both of which elicit immune responses in Arabidopsis cell cultures [44]. A total of 109 differentially phosphorylated residues of membrane-associated proteins on activation of the intracellular RPS2 receptor were identified by phosphoproteomic screening using an inducible expression system of the bacterial effector avrRpt2 in Arabidopsis [45]. Additionally, phosphorylation plays a central role in the progression of the signal through the MAP kinase cascade, which includes a class of protein kinases that plays a crucial signalling role in plant defence against pathogen and herbivore attacks [46]. The expression levels of several MAPKs and mitogen-activated protein kinase kinases (MAPKKs) were significantly upregulated by $S$. graminum feeding in wheat, indicating that MAPK signalling plays critical roles in regulating the induced defence responses of S. graminum.
The expression levels of many WRKY genes were significantly upregulated by $S$. graminum feeding. WRKY transcription factors comprise a large protein family sharing a DNA binding domain of approximately 60 amino acids that contains an invariable sequence WRKYGQK and a zinc-finger-like domain [47, 48]. An increasing number of WRKY TFs have been identified as substrates of MAPKs and important components in MAPK signalling pathways for the regulation of plant immunity [49-51]. For instance, in response to Botrytis cinerea infection, WRKY33 is phosphorylated and activated by MPK3/MPK6, which induce downstream defence responses in Arabidopsis, such as ethylene production [52]. Phospho-mimicking mutants of WRKY transcription factors are involved in the induction of RBOHB-dependent ROS burst and cell death in Nicotiana benthamiana, suggesting that WRKYs are associated with the induction of HR-cell death as MAPK substrates in plants [53]. Whether the MAPK-WRKY pathway is involved in the cell death and chlorosis caused by $S$. graminum is still unknown.

\section{S. graminum feeding induces strong oxidative stress in wheat}

Abiotic and biotic stresses generally induce the accumulation of ROS, such as $\mathrm{H}_{2} \mathrm{O}_{2}$ and $\mathrm{O}^{2}$-, and cause oxidative stress in plants. $\mathrm{H}_{2} \mathrm{O}_{2}$ is one of the most important ROS in plant-pathogen and plant-herbivore interactions and has an important role in signal transmission and plant defence responses [54, 55]. The production of ROS, such as hydrogen peroxide $\left(\mathrm{H}_{2} \mathrm{O}_{2}\right)$, rapidly occurs in fern plants after just $1 \mathrm{~h}$ of herbivory [56, 57]. In infested barley plants, the maximum level of $\mathrm{H}_{2} \mathrm{O}_{2}$ was found just approximately 20 min after aphid infestation [58]. In our study, rapid $\mathrm{H}_{2} \mathrm{O}_{2}$ accumulation was also detected in wheat after S. graminum feeding, which suggested that aphid infestation results in strong oxidative stress. In plant cells, antioxidant enzymes, such as CAT, POD, and SOD keep ROS at low concentrations, avoiding oxidative damage while allowing them to play crucial functions in signal transduction [59]. Excess cellular levels of ROS cause damage to proteins, nucleic acids, lipids, membranes and organelles, which can lead to activation of cell death processes such as apoptosis. The transcriptomic and enzymatic results in our study showed that $S$. graminum feeding increased the gene expression levels and enzyme activities of ROS scavengers in wheat leaves. It is speculated that although ROS scavengers were significantly upregulated by $S$. graminum, $\mathrm{H}_{2} \mathrm{O}_{2}$ production might exceed the cellular antioxidant capacity, resulting in oxidative damage to cellular components and chlorosis in leaves.

Strong SA-dependent defence responses were triggered by $S$ graminum. Considerable evidence demonstrates that 
$\mathrm{H}_{2} \mathrm{O}_{2}$ can interact with plant defence hormones, such as $\mathrm{SA}$ [60]. For example, SA treatment can enhance $\mathrm{H}_{2} \mathrm{O}_{2}$ levels, and $\mathrm{H}_{2} \mathrm{O}_{2}$ has been proposed to function downstream of SA in plants based on the evidence that SA can participate in regulating antioxidant enzymes, such as CAT, SOD and ascorbate peroxidase (APx) [61-63]. In contrast, other studies report that elevated $\mathrm{H}_{2} \mathrm{O}_{2}$ levels could activate SA biosynthesis via stimulation of $\mathrm{BA} 2 \mathrm{H}$ (benzoic acid 2-hydroxylase) activity in tobacco cells [64]. Furthermore, other studies have indicated that $\mathrm{H}_{2} \mathrm{O}_{2}$ does not function downstream of SA in regulating PR protein expression [65]. The mechanisms by which SA interacts with $\mathrm{H}_{2} \mathrm{O}_{2}$ production in plants remain unclear.

\section{NADPH oxidases are involved in the regulation of $S$. graminum-induced $\mathrm{H}_{2} \mathrm{O}_{2}$ accumulation and defence responses of wheat}

Plasma-membrane-localized NADPH oxidases, known as respiratory burst oxidase homologues (Rbohs), are membrane-bound enzyme complexes that are important components for $\mathrm{H}_{2} \mathrm{O}_{2}$ generation and plant immunity [66]. A lack of $\mathrm{RBOH}$ expression leads to very low levels of ROS production, resulting in the alteration of different plant responses in terms of cell death and pathogen resistance [67-69]. To further examine the roles of NADPH oxidases in $\mathrm{H}_{2} \mathrm{O}_{2}$ accumulation and defence responses induced by $S$. graminum feeding, wheat leaves were treated with the NADPH oxidase inhibitor DPI at different concentrations. $\mathrm{H}_{2} \mathrm{O}_{2}$ production and the expression levels of SA-dependent defence genes were inhibited, suggesting the involvement of NADPH oxidases in $\mathrm{H}_{2} \mathrm{O}_{2}$ accumulation and defence responses induced by $S$. graminum feeding. Phosphorylation at specific conserved residues in RBOHD is also required for ROS production in both PAMP-triggered immunity (PTI) and effector-triggered immunity (ETI) and immunity against avirulent bacteria and a virulent necrotrophic fungus [70]. Whether RBOHD phosphorylation is associated with the ROS production, defence responses and chlorosis induced by S. graminum feeding in wheat is worthy of further study.

\section{Conclusions}

In conclusion, the transcriptomic profiling of wheat performed in this study revealed dynamic physiological changes in wheat leaves in response to phytotoxic aphid S. graminum feeding. S. graminum feeding triggered rapid plant defence responses and ROS-scavenging activities in wheat plants. A cytological analysis showed that substantial $\mathrm{H}_{2} \mathrm{O}_{2}$ accumulated in wheat leaves in response to S. graminum feeding. Our results also demonstrated that NADPH oxidases play vital roles in the induction of $\mathrm{H}_{2} \mathrm{O}_{2}$ accumulation and SA-dependent defence responses triggered by $S$. graminum feeding. Our future studies will focus on the mechanisms of chlorosis induction by $S$. graminum feeding and the roles of salivary proteins of aphids in the induction of symptoms in plants.

\section{Methods}

Plants and aphids

Wheat seeds (Triticum aestivum var. Zhongmai175, Shengyuan Seed Industry Technology Co., Ltd., China) were immersed and germinated in sterilized Petri dishes with distilled water for 3-4 days at a temperature of $25 \pm 1^{\circ} \mathrm{C}$ and a photoperiod of 16:8 (L:D) h. After germination, healthy seedlings were selected and transferred into plastic plots containing organic soil and were grown in a climate chamber with a temperature of $20 \pm 1{ }^{\circ} \mathrm{C}$, a relative humidity of $40-60 \%$ and a photoperiod of $\mathrm{L}$ : $\mathrm{D}=16 \mathrm{~h}: 8 \mathrm{~h}$. All S. graminum were initiated from a single parthenogenetic female collected from a wheat field in Langfang city, Hebei Province, northern China. A clonal aphid lineage was maintained on wheat plants (Zhongmai175) under laboratory conditions at $20 \pm 1{ }^{\circ} \mathrm{C}$ and $65 \pm 10 \%$ relative humidity with a photoperiod of 14 : 10 (L: D) h.

\section{Wheat plant infested with aphids}

At the two-leaf stage (12-day-old), twenty 3rd instar $S$. graminum were placed into clip cages on the second leaves of wheat plants. Aphids were gently removed from wheat leaves using a soft brush at different time points after aphid feeding. Leaf tissues at the aphid feeding sites of each plant were collected into a $1.5 \mathrm{ml}$ centrifuge tube using sterilized scissors, transferred to liquid nitrogen immediately and stored at $-80^{\circ} \mathrm{C}$ until use. Two leaf tissues were collected from two independent plants with the same treatment to form one independent biological replicate. Three independent biological replicates were conducted for each treatment. Plants with empty clip cages were set as control groups.

RNA extraction, library construction, and RNA sequencing Total RNA from wheat leaves was extracted with TRIzol reagent (Invitrogen, Carlsbad, CA, USA) according to the manufacturer's instructions. The RNA quality and quantity were examined using a DS-11 spectrophotometer (DeNovix, DE, USA), and the RNA integrity was confirmed using an RNA Nano 6000 Assay Kit with an Agilent 2100 Bioanalyser (Agilent Technologies, Santa Clara, CA, USA). Only RNA samples with an RNA Integrity Number (RIN) $\geq 7.0$ were used in the subsequent analysis. Libraries were constructed using the TruSeq Stranded mRNA LT Sample Prep Kit (Illumina, San Diego, CA, USA) following the protocols provided by the manufacturer and were sequenced on the Illumina sequencing platform (Illumina HiSeq 4000), and 150-bp 
paired-end reads were generated. There were three independent biological replicates for each treatment.

\section{RNA-seq data analysis}

To obtain high-quality reads, the reads containing adaptor sequences, more than 10\% ambiguous bases (noted as N) and low-quality bases (Qphred $\leq 20$ bases account for more than $50 \%$ of the entire read length of the reads) were filtered. The resulting clean reads were then aligned to the wheat reference genome (IWGSC RefSeq v1.0 genome) using TopHat v2.0.12 with the default values [71, 72]. Transcript assembly was performed using Cufflinks v2.1.1 with the default parameters [73]. All transcripts were compared with gene models in the reference genome to identify novel genes expressed from previously intergenic regions (class code " $u$ ") using Cuffcompare [74]. The gene expression levels in all the samples were calculated using fragments per kilobase of exon model per million mapped reads (FPKM), and the genes with more than 1 FPKM in at least one sample of wheat leaves were used for further analysis [75]. An adjusted $P$ value $(\mathrm{FDR}<0.01)$ and fold change $(\mathrm{FC})$ ratio $\left(\left|\log _{2} \mathrm{FC}\right| \geq 1\right)$ were used to determine the differentially expressed genes (DEGs) between aphid-infested and control leaves using DESeq R package. Principal component analysis (PCA) was performed using the DESeq2 package for clustering the samples based on gene expression patterns [76]. The heatmap of DEGs was clustered using pheatmap (version 1.0.8, http://cran.rproject.org/web/packages/pheatmap) package in R. Gene Ontology (GO) (http://geneontology.org/) enrichment analyses of the DEGs were performed to understand the biological significance of the DEGs using the GOseq $R$ package, and GO terms were considered significantly enriched with a corrected $p$-value $<0.05$ [77].

\section{Changes of total chlorophyll levels in wheat leaves after aphid infestation}

Total chlorophyll content in aphid-infested wheat leaves at different time points was examined according to the method of Aron [78] with slight modifications. A total of $100 \mathrm{mg}$ of fresh leaf tissues was ground to a fine powder in liquid nitrogen using a mortar and pestle. Chlorophyll was extracted with $5 \mathrm{~mL}$ of $80 \%$ acetone $(\mathrm{v} / \mathrm{v})$ at $4{ }^{\circ} \mathrm{C}$ for overnight. The homogenate was centrifuged at $4000 \mathrm{~g}$ for $10 \mathrm{~min}$ at $4^{\circ} \mathrm{C}$, and the supernatant was used for chlorophyll assay. Chlorophyll content of leaves was detected spectrophotometrically, by reading the absorbance at 645 and $663 \mathrm{~nm}$ (DU800, Beckman, USA).

\section{Detection of $\mathrm{H}_{2} \mathrm{O}_{2}$ accumulation in wheat leaves induced by aphid feeding}

To detect $\mathrm{H}_{2} \mathrm{O}_{2}$ accumulation in wheat leaves induced by $S$. graminum feeding, 3,3'-diaminobenzidine (DAB)
(Sigma, Germany) staining was performed using the protocols reported by Wang et al. [79] with some modifications. In brief, leaf segments infested with S. graminum were cut off using sterilized scissors, and then immediately immersed in $1 \mathrm{mg} \mathrm{mL}^{-1}$ DAB solution $(10 \mathrm{mmol}$ $\mathrm{L}^{-1} \mathrm{Na}_{2} \mathrm{HPO}_{4}, \mathrm{pH} 3.8$ ) and incubated in a dark chamber overnight at room temperature. Leaves were decolorized in $95 \%$ ethanol solution and hyalinized in saturated chloral hydrate. The stained leaves were then visualized using an Olympus BX-63 microscope (Olympus Corporation, Japan). The endogenous $\mathrm{H}_{2} \mathrm{O}_{2}$ content in the wheat leaves was determined according to the methods described by Ferguson et al. [80].

\section{Determination of antioxidant enzymes in wheat leaves after aphid infestation}

To examine the activities of peroxidase (POD), superoxide dismutase (SOD) and catalase (CAT) in wheat leaves at all time points after aphid infestation, a total of $200 \mathrm{mg}$ of fresh leaf tissues was ground into a fine powder in liquid nitrogen using a mortar and pestle. The powder was then immediately homogenized in $1.5 \mathrm{~mL}$ of ice-cooled $50 \mathrm{mM}$ potassium phosphate buffer $(\mathrm{pH}=7.8)$ containing $0.1 \mathrm{mM}$ EDTA, $1 \mathrm{mM}$ phenylmethylsulfonyl fluoride (PMSF) and 1.0\% (w/v) polyvinylpyrrolidone. The homogenate was centrifuged at $15,000 \mathrm{~g}$ for $30 \mathrm{~min}$ at $4{ }^{\circ} \mathrm{C}$, and supernatant was immediately collected as crude enzyme extract for further assay. The activities of POD, SOD, CAT were determined by following the changes in absorbance at $470 \mathrm{~nm}, 560 \mathrm{~nm}$ and $240 \mathrm{~nm}$ respectively according to previously described [81].

\section{RT-qPCR}

Total RNA was extracted from leaves using TRIzol Reagent (Invitrogen) according to the manufacturer's recommended protocols. The concentration of RNA was measured by a DS-11 Spectrophotometer (DeNovix, DE, USA). One microgram of total RNA was reversetranscribed into first-strand cDNA with oligo dT primers using the EasyScript All-in-One First-Strand cDNA Synthesis SuperMix for RT-qPCR (TransGen Biotech) following the manufacturer's instructions, and cDNA templates were stored at $-20{ }^{\circ} \mathrm{C}$ until use. RTqPCR was performed using the same protocols as previously described [35]. The RT-qPCR protocol consisted of an initial heat activation step of $95^{\circ} \mathrm{C}$ for $10 \mathrm{~min}$, followed by 40 cycles of $95^{\circ} \mathrm{C}$ for $15 \mathrm{~s}$ and $60^{\circ} \mathrm{C}$ for $40 \mathrm{~s}$. Three biological replicates were performed for each treatment, and each biological replicate consisted of three technical replicates.

\section{Wheat seedlings treated with DPI solution}

The leaves of wheat seedlings were treated with $10 \mu \mathrm{M}$ and $25 \mu \mathrm{M}$ diphenylene iodonium (DPI, a NADPH 
oxidase inhibitor) solution or deionized water (control) for $24 \mathrm{~h}$ and then infested with S. graminum for $48 \mathrm{~h}$. Detection of $\mathrm{H}_{2} \mathrm{O}_{2}$ accumulation and expression levels of genes in wheat leaves were conducted as described previously.

\section{Statistical analyses}

All the data were analysed using SPSS Statistics 20.0 software (SPSS Inc., Chicago, IL., USA). Normality of distribution and homogeneity of variances were tested by Shapiro-Wilk's test and Levene's test respectively, and the differences among groups were examined through one-way analysis of variance (Duncan). $P$ values less than 0.05 were considered statistically significant.

\section{Supplementary information}

Supplementary information accompanies this paper at https://doi.org/10. 1186/s12864-020-6743-5.

Additional file 1. Summary for the transcriptome of wheat in response to S. graminum feeding at different time points using Illumina RNA-seq.

Additional file 2. Summary of clean reads mapped to the reference wheat genome.

Additional file 3. All of the differentially expressed genes (DEGs) of wheat leaves in response to S. graminum feeding at 2, 6, 12, 24 and $48 \mathrm{hpi}$.

Additional file 4. Volcano plots of DEGs in wheat leaves induced by $S$. graminum feeding for 2, 6, 12, 24 and $48 \mathrm{~h}$ compared with control. Red spots represent up-regulated DEGs, green spots represent downregulated DEGs and blue spots represent genes with no significant expression.

Additional file 5. Heatmap with hierarchical clustering dendrograms of DEGs in wheat leaves in response to $S$. graminum feeding at 0 (control), 2, 6, 12, 24 and $48 \mathrm{hpi}$. Red indicates higher expression values across treatment, and blue represents lower expression values across treatment.

Additional file 6. $\mathrm{GO}$ enrichment analysis of all of the DEGs of wheat leaves in response to S. graminum feeding at 2 (A), 6 (B), 12 (C), 24 (D) and $48 \mathrm{hpi}(\mathrm{E})$

\section{Abbreviations}

ABA: Abscisic acid; AOC: Allene oxide cyclase; BYDV: Barley yellow dwarf virus; CAT: Catalase; DAB:: 3,3'-diaminobenzidine; DPI: Diphenylene iodonium; ET: Ethylene; FAD: Fatty acid desaturase; FPKM: Fragments per kilobase of exon model per million mapped reads; $\mathrm{H}_{2} \mathrm{O}_{2}$ : Hydrogen peroxide; JA: Jasmonic acid; JAR: Jasmonic acid-amido synthetases; LOX: Lipoxygenase; MAPK: Mitogen-activated protein kinase; MAPKKs: Mitogen activated protein kinase kinases; PCA: Principal component analysis; POD: Peroxidase: PAL: Phenylalanine ammonia-lyase; PTMs: Post-translational modifications; RNA-Seq: High-throughput RNA sequencing; ROS: Reactive oxygen species; SA: Salicylic acid; SEs: Sieve elements; VOCs: Volatile organic compounds

\section{Acknowledgements}

We would like to thank technician Ms. Yanxia Liu for aphid rearing in our laboratory.

\section{Authors' contributions}

JLC and YZ designed the experiment, YZ, YF, QW and XL performed the experiments, $Y Z, Y F$ and $Q L$ analyzed the data, JLC and $Y Z$ provided funding, $Y Z$ and JLC wrote the first drafts of the manuscript. All authors critically read and approved the manuscript.

\section{Funding}

This study was funded by the National Natural Science Foundation of China (31901881, 31871979), National Key R\&D Plan in China (2017YFD0201700,
2017YFD0200900, 2016YFD0300700), State Modern Agricultural Industry Technology System (CARS-22-G-18). The funding organizations played no role in the design of study and collection, analysis, and interpretation of data and in writing the manuscript.

Availability of data and materials

The datasets used and analyzed during the current study are available from the corresponding author on reasonable request.

\section{Ethics approval and consent to participate}

The seeds of wheat, Zhongmai 175 were cultivated by Institute of Crop Sciences, Chinese Academy of Agricultural Sciences and bought from Henan Shengyuan Seed Industry Technology Co., Ltd., Xuchang, China. The authors declare that all the experiments performed in this study comply with the institutional, national, or international guidelines.

\section{Consent for publication}

Not applicable.

\section{Competing interests}

The authors declare that they have no competing interests.

Received: 23 December 2019 Accepted: 20 April 2020

Published online: 04 May 2020

References

1. Kaplan I, Halitschke R, Kessler A, Sardanelli S, Denno RF. Constitutive and induced defenses to herbivory in above- and belowground plant tissues. Ecology. 2008;89(2):392-406.

2. Howe GA, Jander G. Plant immunity to insect herbivores. Annu Rev Plant Bio. 2008;59:41-66.

3. Hariprasad KV, Van Emden HF. Mechanisms of partial plant resistance to diamondback moth (Plutella xylostella) in brassicas. Int J Pest Manag. 2010; 56(1):15-22.

4. Figueiredo AST, Resende JTV, Morales RGF, Gonçalves APS, Silva PRD. The role of glandular and non-glandular trichomes in the negative interactions between strawberry cultivars and spider mite. Arthropod-Plant Interact. 2013;7:53-8.

5. Karley AJ, Mitchell C, Brookes C, McNicol J, O’Neill T, Roberts H, Graham J, Johnson SN. Exploiting physical defence traits for crop protection: leaf trichomes of Rubus idaeus have deterrent effects on spider mites but not aphids. Annu Appl Biol. 2016;168:159-72.

6. Hanley ME, Lamont BB, Fairbanks MM, Raffertyb CM. Plant structural traits and their role in anti-herbivore defence. Perspect Plant Ecol Evol Syst. 2007; 8(4):157-78.

7. Fürstenberg-Hägg J, Zagrobelny M, Bak S. Plant defense against insect herbivores. Int J Mol Sci. 2013;14:10242-97.

8. War A, Paulraj MG, Ahmad T, Buhroo AA, Hussain B, Ignacimuthu S, Sharma HC. Mechanisms of plant defense against insect herbivores. Plant Signal Behav. 2012;7(10):1306-20

9. Carbone SS, Sotelo T, Velasco P, Cartea ME. Antibiotic properties of the glucosinolates of Brassica oleracea var. acephala similarly affect generalist and specialist larvae of two lepidopteran pests. J Pest Sci. 2016;89:195-206.

10. Dudareva N, Negre F, Nagegowda DA, Orlova I. Plant volatiles: recent advances and future perspectives. Crit Rev Plant Sci. 2006;25(5):417-40.

11. Arimura G, Matsui K, Takabayashi J. Chemical and molecular ecology of herbivore-induced plant volatiles: proximate factors and their ultimate functions. Plant Cell Physiol. 2009:50(5):911-23.

12. Tamiru A, Khan ZR, Bruce TJA. New directions for improving crop resistance to insects by breeding for egg induced defence. Curr Opin Insect Sci. 2015; 9:51-5.

13. Staswick PE, Tiryaki I, Rowe ML. Jasmonate response locus JAR1 and several related Arabidopsis genes encode enzymes of the firefly luciferase superfamily that show activity on jasmonic, salicylic, and indole-3-acetic acids in an assay for adenylation. Plant Cell. 2002:14(6):1405-15.

14. Koornneef A, Pieterse-Corne MJ. Cross talk in defense signaling. Plant Physiol. 2008;146(3):839-44

15. Frébortová J, Novák O, Frébort I, Jorda R. Degradation of cytokinins by maize cytokinin dehydrogenase is mediated by free radicals generated by enzymatic oxidation of natural benzoxazinones. Plant J. 2010;61(3):467-81. 
16. Zeier J. New insights into the regulation of plant immunity by amino acid metabolic pathways. Plant Cell Environ. 2013;36(12):2085-103.

17. Westfall CS, Sherp AM, Zubieta C, Alvarez S, Schraft E, Marcellin R, Ramirez L, Jez JM. Arabidopsis thaliana GH3.5 acyl acid amido synthetase mediates metabolic crosstalk in auxin and salicylic acid homeostasis. Proc Natl Acad Sci U S A. 2016;113(48):13917-22.

18. Urano K, Maruyama K, Jikumaru Y, Kamiya Y, Yamaguchi-Shinozaki K, Shinozaki K. Analysis of plant hormone profiles in response to moderate dehydration stress. Plant J. 2017;90(1):17-36.

19. Wu JQ, Baldwin IT. New insights into plant responses to the attack from insect herbivores. Annu Rev Genet. 2010;44:1-24.

20. Walling LL. The myriad plant responses to herbivores. J Plant Growth Regul. 2000;19:195-216.

21. Glazebrook J. Contrasting mechanisms of defense against biotrophic and necrotrophic pathogens. Annu Rev Phytopathol. 2005;43:205-27.

22. Kei K, Atsushi M, Yukie S, Sugeno W, Murata M, Seo S, Mitsuhara I. Different expression profiles of jasmonic acid and salicylic acid inducible genes in the tomato plant against herbivores with various feeding modes. Arthropod Plant Interact. 2012;6:221-30.

23. Tjallingii WF. Salivary secretions by aphids interacting with proteins of phloem wound responses. J Exp Bot. 2006;57(4):739-45.

24. Walling LL. Avoiding effective defenses: strategies employed by phloemfeeding insects. Plant Physiol. 2008;146(3):859-66.

25. Virendra G. Aphids on the world's crops. An identification and information guide. Orient Insects. 2001:35:104.

26. Mojahed S, Razmjou J, Golizadeh A, Naseri B. Resistance of wheat cultivars and lines to Schizaphis graminum (Hemiptera: Aphididae) under laboratory conditions. Appl Entomol Zool. 2013;48:39-45.

27. Aljaryian R, Kumar L. Changing global risk of invading greenbug Schizaphis graminum under climate change. Crop Prot. 2016;88:137-48.

28. Park SJ, Huang YH, Ayoubi P. Identification of expression profiles of sorghum genes in response to greenbug phloem-feeding using CDNA subtraction and microarray analysis. Planta. 2006;223(5):932-47.

29. Donze-Reiner T, Palmer NA, Scully ED, Prochaska TJ, Koch KG, Heng-Moss T, Bradshaw JD, Twigg P, Amundsen K, Sattler SE, Sarath G. Transcriptional analysis of defense mechanisms in upland tetraploid switchgrass to greenbugs. BMC Plant Biol. 2017;17(1):46.

30. Vincent TR, Avramova M, Canham J, Higgins P, Bilkey N, Mugford ST, Pitino M, Toyota M, Gilroy S, Miller AJ, Hogenhout SA, Sanders D. Interplay of plasma membrane and vacuolar ion channels, together with BAK1, elicits rapid cytosolic calcium elevations in Arabidopsis during aphid feeding. Plant Cell. 2017;29(6):1460-79.

31. Niu L, Pan L, Zeng WF, Lu ZH, Cui GC, Fan ML, Xu Q, Wang ZQ, Li GH. Dynamic transcriptomes of resistant and susceptible peach lines after infestation by green peach aphids (Myzus persicae Sülzer) reveal defence responses controlled by the Rm3 locus. BMC Genomics. 2018;19(1):846.

32. Tzin $V$, Fernandez-Pozo N, Richter A, Schmelz EA, Schoettner M, Schäfer M, Ahern KR, Meihls LN, Kaur H, Huffaker A, Mori N, Degenhardt J, Mueller LA, Jander $\mathrm{G}$. Dynamic maize responses to aphid feeding are revealed by a time series of transcriptomic and metabolomic assays. Plant Physiol. 2015; 169(3):1727-43.

33. Morgham AT, Richardson PE, Campbell RK, Burd JD, Eikenbary RD, Sumner LC. Ultrastructural responses of resistant and susceptible wheat to infestation by greenbug biotype E (Homoptera: Aphididae). Ann Entomol Soc Am. 1994;87(6):908-17.

34. Miles PW. Aphid saliva. Biol Rev. 1999;74(1):41-85.

35. Zhang Y, Fan J, Fu Y, Francis F, Chen JL. Plant-mediated interactions between two cereal aphid species: promotion of aphid performance and attraction of more parasitoids by infestation of wheat with phytotoxic aphid Schizaphis graminum. J Agric Food Chem. 2019;67(10):2763-73.

36. Züst T, Agrawal AA. Mechanisms and evolution of plant resistance to aphids. Nature Plants. 2016;2:15206.

37. Zhao LY, Chen JL, Cheng DF, Sun JR, Liu Y, Tian Z. Biochemical and molecular characterizations of Sitobion avenae-induced wheat defense responses. Crop Prot. 2009;28(5):435-42.

38. Zhu-Salzman K, Salzman RA, Ahn JE, Koiwa H. Transcriptional regulation of sorghum defense determinants against a phloem-feeding aphid. Plant Physiol. 2004;134(1):420-31.

39. Smith CM, Liu XM, Wang LJ, Liu X, Chen MS, Starkey S, Bai JF. Aphid feeding activates expression of a transcriptome of oxylipin-based defense signals in wheat involved in resistance to herbivory. J Chem Ecol. 2010;36(3):260-76.
40. Reddy SK, Weng Y, Rudd JC, Akhunova A, Liu SY. Transcriptomics of induced defense responses to greenbug aphid feeding in near isogenic wheat lines. Plant Sci. 2013;212:26-36.

41. Staswick PE, Tiryaki I. The oxylipin signal jasmonic acid is activated by an enzyme that conjugates it to isoleucine in Arabidopsis. Plant Cell. 2004;16(8): 2117-27.

42. Olsen JV, Blagoev B, Gnad F, Macek B, Kumar C, Mortensen P, Mann M. Global, in vivo, and site-specific phosphorylation dynamics in signaling networks. Cell. 2006;127(3):635-48.

43. Tena G, Boudsocq M, Sheen J. Protein kinase signaling networks in plant innate immunity. Curr Opin Plant Biol. 2011;14(5):519-29.

44. Keyse SM. Protein phosphatases and the regulation of mitogen-activated protein kinase signaling. Curr Opin Cell Biol. 2000;12(2):186-92.

45. Kadota Y, Liebrand TWH, Goto Y, Sklenar J, Derbyshire P, Menke FLH, Torres MA, Molina A, Zipfel C, Coaker G, Shirasu K. Quantitative phosphoproteomic analysis reveals common regulatory mechanisms between effector- and PAMP-triggered immunity in plants. New Phytol. 2019;221(4):2160-75.

46. Asai T, Tena G, Plotnikova J, Willmann MR, Chiu WL, Gomez-Gomez L, Boller T, Ausubel FM, Sheen J. MAP kinase signalling cascade in Arabidopsis innate immunity. Nature. 2002;415(6875):977-83.

47. Rushton PJ, Torres JT, Parniske M, Wernert P, Hahlbrock K, Somssich IE. Interaction of elicitor-induced DNA-binding proteins with elicitor response elements in the promoters of parsley PR1 genes. EMBO J. 1996;15(20):5690700.

48. Yamasaki K, Kigawa T, Inoue M, Tateno M, Yamasaki T, Yabuki T, Aoki M, Seki E, Matsuda T, Tomo Y, Hayami N, Terada T, Shirouzu M, Tanaka A, Seki M, Shinozaki K, Yokoyama S. Solution structure of an Arabidopsis WRKY DNA binding domain. Plant Cell. 2005;17(3):944-56.

49. Mao GH, Meng XZ, Zheng ZY, Chen ZX, Zhang SQ. Phosphorylation of a WRKY transcription factor by two pathogen-responsive MAPKs drives phytoalexin biosynthesis in Arabidopsis. Plant Cell. 2011;23(4):1639-53.

50. Liu YD, Zhang SQ. Phosphorylation of 1-aminocyclopropane-1-carboxylic acid synthase by MPK6, a stress-responsive mitogen-activated protein kinase, induces ethylene biosynthesis in Arabidopsis. Plant Cell. 2004;16(12): 3386-99.

51. Zheng ZY, Qamar SA, Chen ZX, Mengiste T. Arabidopsis WRKY33 transcription factor is required for resistance to necrotrophic fungal pathogens. Plant J. 2006:48(4):592-605.

52. Li GJ, Meng XZ, Wang RG, Mao GH, Han L, Liu YD, Zhang SQ. Dual-level regulation of ACC synthase activity by MPK3/MPK6 cascade and its downstream WRKY transcription factor during ethylene induction in Arabidopsis. PLoS Genet. 2012;8(6):e1002767.

53. Adachi H, Nakano T, Miyagawa N, Ishihama N, Yoshioka M, Katou Y, Yaeno T, Shirasu K, Yoshioka H. WRKY transcription factors phosphorylated by MAPK regulate a plant immune NADPH oxidase in Nicotiana benthamiana. Plant Cell. 2015;27(9):2645-63.

54. Maffei ME, Mithöfer A, Arimura Gl, Uchtenhagen H, Bossi S, Bertea CM, Cucuzza LS, Novero M, Volpe V, Quadro S, Boland W. Effects of feeding Spodoptera littoralis on lima bean leaves. III. Membrane depolarization and involvement of hydrogen peroxide. Plant Physiol. 2006;140(3):1022-35.

55. Maffei M, Mithöfer A, Boland W. Insects feeding on plants: rapid signals and responses preceding the induction of phytochemical release. Phytochemistry. 2007;68(22-24):2946-59.

56. Bolwell GP, Bindschedler LV, Blee KA, Butt VS, Davies DR, Gardner SL, Gerrish C, Minibayeva F. The apoplastic oxidative burst in response to biotic stress in plants: a three-component system. J Exp Bot. 2002;53(372):1367-76.

57. Maffei M, Mithöfer A, Boland W. Before gene expression: early events in plant-insect interaction. Trends Plant Sci. 2007;12(7):310-6.

58. Argandoña VH, Chaman M, Cardemil L, Muñoz O, Zúñiga GE, Corcuera LJ. Ethylene production and peroxidase activity in aphid-infested barley. J Chem Ecol. 2001;27(1):53-68.

59. Kuśnierczyk A, Winge P, Jørstad TS, Troczyńska J, Rossiter JT, Bones AM. Towards global understanding of plant defence against aphidstiming and dynamics of early Arabidopsis defence responses to cabbage aphid (Brevicoryne brassicae) attack. Plant Cell Environ. 2008; 31(8):1097-115.

60. Yang W, Zhu CH, Ma XL, Li GJ, Gan LJ, Denny N, Xia K. Hydrogen peroxide is a second messenger in the salicylic acid-triggered adventitious rooting process in mung bean seedlings. PLoS One. 2013;8(12):e84580.

61. Rao MV, Paliyath G, Ormrod DP, Murr DP, Watkins CB. Influence of salicylic acid on $\mathrm{H}_{2} \mathrm{O}_{2}$ production, oxidative stress, and $\mathrm{H}_{2} \mathrm{O}_{2}$-metabolizing enzymes 
(salicylic acid mediated oxidative damage requires $\mathrm{H}_{2} \mathrm{O}_{2}$ ). Plant Physiol. 1997:115(1):137-49.

62. Dat JF, Lopez-Delgado H, Foyer $\mathrm{CH}$, Scott IM. Parallel changes in $\mathrm{H}_{2} \mathrm{O}_{2}$ and catalase during thermo tolerance induced by salicylic acid or heat acclimation in mustard seedlings. Plant Physiol. 1998;1 16(4):1351-7.

63. Mateo A, Funck D, Mühlenbock P, Kular B, Mullineaux PM, Karpinski S. Controlled levels of salicylic acid are required for optimal photosynthesis and redox homeostasis. J Exp Bot. 2006;57(8):1795-807.

64. Leon J, Lawton MA, Raskin I. Hydrogen peroxide stimulates salicylic acid biosynthesis in tobacco. Plant Physiol. 1995;108(4):1673-8.

65. Bi YM, Kenton P, Mur L, Darby R, Draper J. Hydrogen peroxide does not function downstream of salicylic acid in the induction of PR protein expression. Plant J. 1995;8(2):235-45.

66. Marino D, Dunand C, Puppo A, Pauly N. A burst of plant NADPH oxidases. Trends Plant Sci. 2012;17(1):9-15.

67. Torres MA, Dangl JL, Jones JD. Arabidopsis gp91 phox homologues AtrbohD and AtrbohF are required for accumulation of reactive oxygen intermediates in the plant defense response. Proc Natl Acad Sci U S A. 2002;99(1):517-22.

68. Mersmann S, Bourdais G, Rietz S, Robatzek S. Ethylene signaling regulates accumulation of the FLS2 receptor and is required for the oxidative burst contributing to plant immunity. Plant Physiol. 2010;154(1):391-400.

69. Berrocal-Lobo M, Stone S, Yang X, Antico J, Callis J, Ramonell KM, Somerville S. ATL9, a RING zinc finger protein with E3 ubiquitin ligase activity implicated in chitin- and NADPH oxidase- mediated defense responses. PLoS One. 2010;5(12):e14426.

70. Liu Z, Zhang Z, Faris JD, Oliver RP, Syme R, McDonald MC, McDonald BA, Solomon PS, Lu S, Shelver WL, Xu S, Friesen TL. The cysteine rich necrotrophic effector SnTox 1 produced by Stagonospora nodorum triggers susceptibility of wheat lines harboring Snn1. PLoS Pathog. 2012;8(1): e1002467.

71. Kim D, Pertea G, Trapnell C, Pimentel H, Kelley R, Salzberg SL. TopHat2: accurate alignment of transcriptomes in the presence of insertions, deletion and gene fusions. Genome Biol. 2013;14(4):R36.

72. International Wheat Genome Sequencing Consortium (IWGSC). Shifting the limits in wheat research and breeding using a fully annotated reference genome. Science. 2018;361(6403):7191.

73. Trapnell C, Williams BA, Pertea G, Mortazavi A, Kwan G, van Baren MJ, Salzberg SL, Wold BJ, Pachter L. Transcript assembly and quantification by RNA-Seq reveals unannotated transcripts and isoform switching during cell differentiation. Nat Biotechnol. 2010;28(5):511-5.

74. Roberts A, Pimentel H, Trapnell C, Pachter L. Identification of novel transcripts in annotated genomes using RNA-Seq. Bioinformatics. 2011; 27(17):2325-9.

75. Mortazavi A, Williams BA, McCue K, Schaeffer L, Wold B. Mapping and quantifying mammalian transcriptomes by RNA-Seq. Nat Methods. 2008;5(7): $621-8$.

76. Anders S, Huber W. Differential expression of RNA-Seq data at the gene level-the DESeq package. Heidelberg: European Molecular Biology Laboratory (EMBL); 2012.

77. Young MD, Wakefield MJ, Smyth GK, Oshlack A. Gene ontology analysis for RNA-seq: accounting for selection bias. Genome Biol. 2010;11(2):R14.

78. Arnon DI. Copper enzymes in isolated chloroplasts: polyphenoloxidase in Beta vulgaris. Plant Physiol. 1949;24(1):1-15.

79. Wang CF, Huang LL, Buchenauer H, Han QM, Zhang HC, Kang ZS. Histochemical studies on the accumulation of reactive oxygen species $\left(\mathrm{O}_{2}{ }^{-}\right.$and $\left.\mathrm{H}_{2} \mathrm{O}_{2}\right)$ in the incompatible and compatible interaction of wheat Puccinia striiformis f. sp. tritici. Physiol Mol Plant Pathol. 2007;71(4-6):230-9.

80. Ferguson IB, Watkins CB, Harman JE. Inhibition by calcium of senescence of detached cucumber cotyledons effect on ethylene and hydroperoxide production. Plant Physiol. 1983;71(1):182-6.

81. Jiang $L$, Yang $H$. Prometryne-induced oxidative stress and impact on antioxidant enzymes in wheat. Ecotoxicol Environ Saf. 2009;72:1687-93.

\section{Publisher's Note}

Springer Nature remains neutral with regard to jurisdictional claims in published maps and institutional affiliations.

\section{Ready to submit your research? Choose BMC and benefit from}

- fast, convenient online submission

- thorough peer review by experienced researchers in your field

- rapid publication on acceptance

- support for research data, including large and complex data types

- gold Open Access which fosters wider collaboration and increased citations

- maximum visibility for your research: over $100 \mathrm{M}$ website views per year

At BMC, research is always in progress.

Learn more biomedcentral.com/submissions 